\title{
Bioconversion enhances anti-oxidant and anti-inflammation activities of different parts of the Mulberry Tree (Morus alba L.), especially the leaf (Mori Folium)
}

\author{
So-Hyun Chon ${ }^{1} \cdot$ Min-A Kim ${ }^{1} \cdot$ Han-Saem Lee ${ }^{1} \cdot$ Jeong-Eun Park $^{1} \cdot$ Yu-Mi Lim ${ }^{1}$. \\ Eun-Jeong Kim ${ }^{1} \cdot$ Eun-Kyung Son ${ }^{1} \cdot$ Sang-Jun Kim ${ }^{2} \cdot J^{2}$ ai-Hyun So ${ }^{1}$ (D)
}

Received: 3 December 2018 / Accepted: 9 January 2019 / Published Online: 30 June 2019

(C) The Korean Society for Applied Biological Chemistry 2019

\begin{abstract}
The mulberry tree (Morus alba L.) has been traditionally used in Chinese medicine to treat inflammatory diseases. We investigated the effects of bioconversion on different components of the mulberry tree, and determined changes in the physiological activities. Ethyl acetate-soluble fractions of five different segments (fruit, Mori Fructus; leaf, Mori Folium; twig, Mori Ramulus; root, Mori Cortex; and mistletoe, Loranthi Ramulus) of the mulberry tree show enhanced anti-oxidant effects in the 2,2-diphenyl-1-picrylhydrazyl, and 2,2'-azinobis-(3-ethylvenzothiazoline-6-sulfonic acid) assays, and enhanced anti-inflammatory effects of lipopolysaccharide (LPS)-stimulated nitric oxide (NO) production in RAW 264.7 macrophages, after being treated with a crude enzyme extract from Aspergillus kawachii, in the following order of activity: Mori Folium $>$ Mori Cortex $>$ Mori Ramulus $>$ Mori Fructus $>$ Loranthi Ramulus. Ethyl acetate- soluble fraction of mulberry leaves (Mori Folium) that underwent bioconversion was most effective, and was devoid of any cytotoxicity. The fraction was also effective against mRNA expression of LPS-induced proinflammatory cytokines, such as inducible nitric oxide synthase, cyclooxygenase- 2 , tumor necrosis factor- $\alpha$, interleukin- $1 \beta$, and interleukin-6. In addition, the fraction was effective in LPSinduced phosphorylation of mitogen-activated protein kinases and
\end{abstract}

Jai-Hyun So $(\square)$

E-mail: dukeny@nikom.or.kr

${ }^{1}$ National Development Institute of Korean Medicine, 94, Hwarang-ro, Gyeongsan, Gyeongbuk 38540, Republic of Korea

${ }^{2}$ Department of Natural Science, Republic of Korea Naval Academy, Gyeongnam, 51704, Republic of Korea

This is an Open Access article distributed under the terms of the Creative Commons Attribution Non-Commercial License (http://creativecommons. org/licenses/by-nc/3.0/) which permits unrestricted non-commercial use, distribution, and reproduction in any medium, provided the original work is properly cited.
IKK, and IKB degradation, followed by translocation of the nuclear factor- $\kappa \mathrm{B}$ from the cytoplasm to the nucleus. Thus, bioconversion increased the anti-oxidative and anti-inflammatory activities of the mulberry leaf.

Keywords Anti-inflammation · Anti-oxidant - Bioconversion Macrophages · Mori Folium · Morus alba L.

\section{Introduction}

Recently, bioconversion by food-processing techniques, such as enzyme treatment (fermentation) has been studied to enhance the beneficial effects of medicinal herbs by changing the content of active components $[1,2]$. In addition, enzyme mediated synthesis or degradation of glycosides has been examined to enhance biologically important compounds [3]. Thus, enzyme treatment techniques may be promising tools for improving the biological activities of medicinal herbs.

Antioxidants have been used as the most promising therapy for the prevention and treatment of several diseases such as cardiovascular disorders, cancer, neurodegenerative diseases, and inflammatory diseases [4]. Reactive oxygen species (ROS) induced oxidative stress, including damage to cell matrices, and antioxidant activity can suppress oxidative damage to organic molecules [5]. ROS have an important role in chronic inflammation as they activate pro-inflammatory cytokines, a major mechanism of inflammatory diseases [6]. Antioxidants can attenuate inflammation. Inflammation is a multi-step process, and several classic symptoms, such as pain, redness, swelling, heat, and loss of function [7]. Nowadays, prevalence of inflammatory diseases has become a public health concern. LPS, a complex glycolipid found in the outer membrane of gram-negative bacteria, plays on important 
role as a strong bacterial virulence factor that triggers inflammation [8-10]. Inflammatory stimuli by LPS lead to the activation of transcription factors such as Nuclear factor kappa B (NF- $\kappa \mathrm{B})$ and mitogen-activated protein kinase (MAPK), which promote the expression of several pro-inflammatory cytokines, including tumor necrosis factor- $\alpha$ (TNF- $\alpha$ ), interleukin- $1 \beta$ (IL-1 $\beta$ ), interleukin- 6 (IL-6), and other inflammatory mediators, such as NO synthesized by inducible nitric oxide synthase (iNOS) and cyclooxygenase-2 (COX-2) [11-13].

The mulberry tree (Morus alba L.) is native to warm and subtropical regions of Asia, Africa, and the Americas. It is widely used as a functional food, herbal medicine, and tea [14]. In addition, it is used to treat and prevent various chronic diseases and as a general tonic to enhance health in traditional oriental medicine. Extract from the mulberry tree has potent antioxidant activity [15], antitumor activity [16], hypolipidemic effect [17,18], macrophage activating effect [19], and neuroprotective activity [20,21]. However, comparison of the effects of bioconversion on the anti-oxidant and anti-inflammatory activities of different parts of the mulberry tree (Morus alba L.) has not yet been performed. The aim of this study was to determine whether bioconversion changed the radical-scavenging effect and anti-inflammatory activities of the mulberry tree on LPS-treated RAW 264.7 cells. Moreover, the part of the mulberry tree that showed increased effects due to bioconversion was identified.

\section{Materials and Methods}

\section{Chemicals}

Extraction solvents, namely $n$-hexane, ethyl acetate (EtOAc), methanol $(\mathrm{MeOH})$, and $n$-butanol $(n-\mathrm{BuOH})$, were purchased from Duksan Chemical (Anseong, Korea). Ultra performance liquid chromatography (UPLC) grade acetonitrile $(\mathrm{MeCN})$ and acetic acid (HOAc) were obtained from Merck (Darmstadt, Germany). Optical density (OD) was measured using a microplate reader (SPECTROstar Nano BMG Labtech). 2,2-Diphenyl-1picrylhydrazyl (DPPH), 2,20-azino-bis(3-ethylbenzothiazoline-6sulfonic acid) diammonium salt (ABTS), LPS, and 3-(4,5dimethylthiazol-2-yl)-2,5-diphenyltetrazolium bromide (MTT) were purchased from Sigma-Aldrich Co. (St. Louis, MO, USA). Dulbecco's modified Eagle's medium (DMEM), fetal bovine serum (FBS), penicillin streptomycin (Pen Strep) were obtained from Gibco (Invitrogen Life Technologies Corporation, NY, USA). Antibodies against iNOS, JNK, p-JNK, ERK, p-ERK, p38,

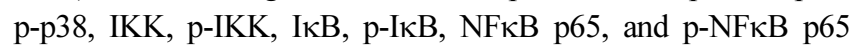
were purchased from Cell Signaling (Boston, MA, USA) and COX-2 was purchased from Abcam (Cambridge, MA, USA). Antibodies against anti-mouse and anti-rabbit secondary antibodies were obtained from Santa Cruz Biotechnology (Santa Cruz, CA, USA). The nuclear extraction kit was purchased from Abcam.

\section{Plant material and preparation of crude enzyme extract}

Mori Fructus and Mori Folium were purchased from Omniherb (Young cheon, Korea) and Mori Ramulus and Mori Cortex were obtained from Humanherb in Daegu, Korea in March, 2015. Loranthi Ramulus was purchased from a local market in Daegu, Korea on the same day. A voucher specimen has been stored at the National Development Institute of Korean Medicine (NIKOM). Five different parts of mulberry trees $(500 \mathrm{~g})$ were refluxed twice with $70 \%$ methanol $(3.5 \mathrm{~L})$ for $3 \mathrm{~h}$. The extracted solution was filtered and evaporated using a rotary evaporator. Crude enzyme extract of Aspergillus kawachii was prepared using a previously described method report [1]. This crude enzyme extract contained $0.260 \mathrm{U} / \mathrm{mL}(1 \mathrm{U}$ is defined as the enzyme activity needed to produce $1 \mathrm{mmol}$ of $\mathrm{p}$-nitrobenzene from $\mathrm{p}$-nitrophenyl- $\beta$-D-glucopyranoside per min) of $\beta$-glucosidase activity. First, $10 \mathrm{~mL}$ of $1 \%$ glucose solution and $10 \mathrm{~g}$ of wheat bran were mixed and sterilized at $121^{\circ} \mathrm{C}$ for $30 \mathrm{~min}$. A. kawachii was inoculated and incubated for 5 days at $30{ }^{\circ} \mathrm{C}$ and then, mixed with $30 \mathrm{~mL}$ of $100 \mathrm{mM}$ sodium phosphate buffer ( $\mathrm{pH} 7$ ) for $5 \mathrm{~h}$ at $18^{\circ} \mathrm{C}$. The mixture was centrifuged for $15 \mathrm{~min}$ at $12000 \mathrm{rpm}$, and the supernatant was collected.

\section{Bioconversion}

Methanolic extracts $(10 \mathrm{~g}, 70 \%)$ of five different parts of the mulberry tree were suspended in $100 \mathrm{~mL}$ of distilled water and treated with $100 \mathrm{~mL}$ of the crude enzyme extract for $12 \mathrm{~h}$ at $37^{\circ} \mathrm{C}$ Inactivated enzyme-treated extracts were used as the control. The inactivated crude enzyme extract was inactivated by autoclaving for $30 \mathrm{~min}$ at $121^{\circ} \mathrm{C}$. Each sample of the activated enzyme-treated extracts and inactivated enzyme-treated extracts (control) was consecutively partitioned with $n$-hexane, EtOAc, and $n$-BuOH and then evaporated.

\section{UPLC conditions analyzing}

Changes compounds during bioconversion were quantified using Waters UPLC (ACQUITY Ultra Performance LC systems H class) with the wavelength set at $280 \mathrm{~nm}$. The samples were dissolved to $0.5 \mathrm{mg} / \mathrm{mL}$ in $\mathrm{MeOH}$ and filtered through a $0.22 \mu \mathrm{m}$ membrane filter, and $2 \mu \mathrm{L}$ of the filtrate was analyzed. UPLC analyses were performed using an ACQUITY UPLC CSH C18 $(2.1 \times 100 \mathrm{~mm}$, $1.7 \mu \mathrm{m}$; Waters, Milford, MA, USA) reverse phase column, and the mobile phase consisted of water (solvent A) and $\mathrm{MeCN}$ (solvent B), each containing $0.1 \%$ HOAc. After the sample was injected into the column, solvent B was increased to $100 \%$ in 10 min and then decreased to $0 \%$ in $1 \mathrm{~min}$ and held at $0 \%$ for $1 \mathrm{~min}$. The solvent flow rate was $0.3 \mathrm{~mL} / \mathrm{min}$.

\section{Measurement of anti-oxidative activities DPPH radical scavenging assay}

The DPPH assay was based on the method reported by Blois et al [22]. A solution of $190 \mu \mathrm{L}$ of $150 \mu \mathrm{M}$ DPPH and $2 \mu \mathrm{L}$ of the 
sample was mixed and incubated at $25^{\circ} \mathrm{C}$ in the dark. Absorbance of the samples and blanks at $517 \mathrm{~nm}$ was determined after $30 \mathrm{~min}$. The result was calculated using Eq. (1):

$$
\text { Radical scavenging assay }(\%)=\frac{C-S}{C} \times 100
$$

where $\mathrm{C}$ and $\mathrm{S}$ are absorbances values of the blank and tested samples, respectively. Three measurements were performed for each tested sample.

\section{$\mathrm{ABTS}^{\circ+}$ radical scavenging assay}

The ABTS assay was performed according to the modified method used by Re et al. [23]. Briefly, $7 \mathrm{mM}$ ABTS was mixed with $2.45 \mathrm{mM}$ potassium persulfate $(2: 1, \mathrm{v} / \mathrm{v})$ and maintained for 12-16 $\mathrm{h}$ in the dark. Then, the $\mathrm{ABTS}^{\cdot+}$ radical solution was diluted in $5 \mathrm{mM}$ phosphate buffer ( $\mathrm{pH}$ 7.4) until the absorbance of the solution was $0.7 \pm 0.02$ at $734 \mathrm{~nm} ; 2 \mu \mathrm{L}$ of the sample and $198 \mu \mathrm{L}$ of the solution were incubated for $1 \mathrm{~min}$ and detected at $734 \mathrm{~nm}$. The result was also estimated using Eq. (1).

\section{Determination of anti-inflammatory activities Cell culture}

Murine RAW 264.7 macrophage cell line was purchased from the Korea Cell Line Bank (KCLB, Seoul, Korea). The cells were maintained in DMEM containing $10 \%$ FBS and penicillin (100 U/ $\mathrm{mL}) /$ streptomycin $(100 \mu \mathrm{g} / \mu \mathrm{L})$ at $37{ }^{\circ} \mathrm{C}$ in a $5 \% \mathrm{CO}_{2}$ humidified incubator. The medium was changed once every $24 \mathrm{~h}$. Stock cells were passaged 2 to 3 times per week. In all experiments, treated samples were dissolved in dimethyl sulfoxide (DMSO), and cells grown to $80 \%$ confluence were pretreated with samples at various concentrations for $1 \mathrm{~h}$ and then treated with LPS $(1 \mu \mathrm{g} / \mathrm{mL})$.

\section{Cell viability assay and NO measurement}

Cell viability was determined using the MTT assay. Briefly, cells were plated at a density of $5 \times 10^{4}$ cells/well in 96-well plates and incubated for $24 \mathrm{~h}$. The cells were treated with samples at different concentrations $(0-50 \mu \mathrm{g} / \mathrm{mL})$ for $1 \mathrm{~h}$, followed by stimulation with LPS. After $24 \mathrm{~h}$, cell-free supernatant was collected for measuring NO production, and rest of the media was suctioned and, $100 \mu \mathrm{L}$ MTT $(0.5 \mathrm{mg} / \mathrm{mL})$ was added and maintained for $4 \mathrm{~h}$ at $37^{\circ} \mathrm{C}$. The supernatant was removed and formazan was dissolved with 100 $\mu \mathrm{L} /$ well of DMSO. Absorbance of formazan was measured at 570 $\mathrm{nm}$, and the amount of formazan was calculated as the percentage of cells. NO production was measured using the collected supernatant before the MTT assay; $100 \mu \mathrm{L}$ of the supernatant was mixed with an equal volume of Griess reagent and allowed to react at room temperature for $10 \mathrm{~min}$ in the dark. Then, absorbance was measured at $550 \mathrm{~nm}$, and nitrite content was calculated on the basis of the standard a $\mathrm{NaNO}_{2}$ curve.
RNA extraction and reverse transcriptase polymerase chain reaction (RT-PCR)

RAW 264.7 cells were seeded at a density of $1 \times 10^{6}$ cells/well in 6 well plates and treated with samples for $1 \mathrm{~h}$ before stimulation with LPS. After $24 \mathrm{~h}$, total cellular RNA was isolated with TRIzol (TRI Reagent), according to the manufacturer's instructions. From each sample, $1 \mu \mathrm{g}$ of RNA was reverse-transcribed (RT) using TaKaRa Ex Taq, $1 \mathrm{mM}$ deoxyribonucleotide triphosphate (dNTP), and $0.5 \mu \mathrm{g} / \mu \mathrm{L}$ of oligo dT Primer. Complementary DNA fragment was amplified for 30 cycles in a volume of $50 \mu \mathrm{L}$ containing 1

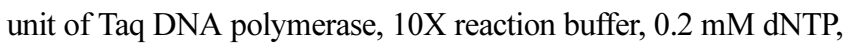
and 100 pmol of $5^{\prime}$ and $3^{\prime}$ primers. Cycling conditions were $98^{\circ} \mathrm{C}$ for $10 \mathrm{~s}$, annealing at $55^{\circ} \mathrm{C}$ for $30 \mathrm{~s}$, and extension at $72{ }^{\circ} \mathrm{C}$ for 1 min. Primers sequences used in this study were purchased from MACRO GEN (Seoul, Korea) and are listed below: for iNOS sense 5'-CCCTTCCGAAGTTTCTGGCAGCAGC-3', antisense 5'-GGCTGTCAGAGCCTCGT GGCTTTGG-3', COX-2 sense 5'CACTACATCCTGACCCACTT-3', antisense 5'-ATGCTCCTGC TTGAGTATGT-3', TNF- $\alpha$ sense 5'-TTGACCTCAGCGCTGAGT TG-3', antisense 5'-CCTGTAGCCCACGTCGTAGC-3', IL-6 sense 5'-GTACTCCAGAAGACCAGAGG-3', antisense 5'-TGCTGGT GACAACCACGGCC-3', IL-1 $\beta$ sense 5'-CAGGATGAGGACAT GAGCACC-3', antisense 5'-CTCTGCAGACTCAAACTCCAC3', $\beta$-actin sense 5'-GTGGGCCGCCCTAGGCACCAG-3', and antisense 5'-GGAGGAAGAGGATGCGGCAGT-3' [24]. After amplification, the PCR products were electrophoresed on $2 \%$ agarose gel and visualized by staining with ethidium bromide. Quantitative analysis of PCR bands was performe using the Fusion Solo 5 gel documentation system (Vilber Lourmat, France).

\section{Western blot}

Pellets of RAW264.7 cells were prepared described in RNA extraction and RT-PCR and lysed using PRO-PREP buffer (iNtRON Biotechnology, Seoul, Korea) at $4{ }^{\circ} \mathrm{C}$ for $30 \mathrm{~min}$ and centrifuged at $12000 \mathrm{rpm}$ for $10 \mathrm{~min}$ for extracting cytosolic proteins. Nuclear proteins were extracted using the Nuclear Protein Extraction Kit (Abcam). Proteins in the cell lysates or nuclear extracts were quantified with the BCA protein assay kit (Thermo Fisher Scientific, Waltman, MA, USA), and concentration was fixed for each sample. The proteins were separated using $8 \%$ sodium dodecylsulfate-polyacrylamide gel electrophoresis and then transferred to polyvinylidine difluoride membranes. The membranes were blocked using TBST (20 mM Tris-HCl, $150 \mathrm{~m}$ $\mathrm{NaCl}$, and $0.1 \%$ Tween-20) containing 5\% skim milk at room temperature for $1 \mathrm{~h}$ on a rotary shaker. Then, specific primary antibodies and the membranes were incubated at room temperature for $1 \mathrm{~h}$ and washed with TBST. Subsequently, the membranes were incubated with secondary antibodies. The blots were visualized using Fusion Solo 5 (Vilber Lourmat, France) with the 
enhanced chemiluminescence kit solution (DOGEN, Seoul, Korea). Relative amounts of each band were analyzed using Image J software.

\section{Before bioconversion}

(Inactivated crude enzyme + extract)

(A)

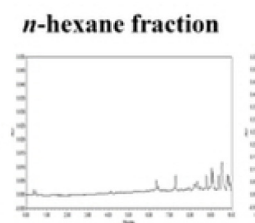

(B)

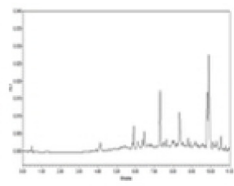

(C)

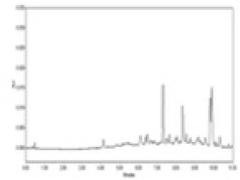

(D)

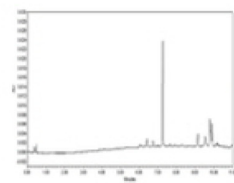

(E)

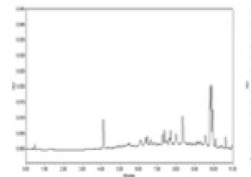

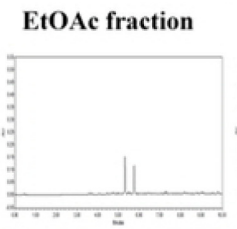

$n$-BuOH fraction
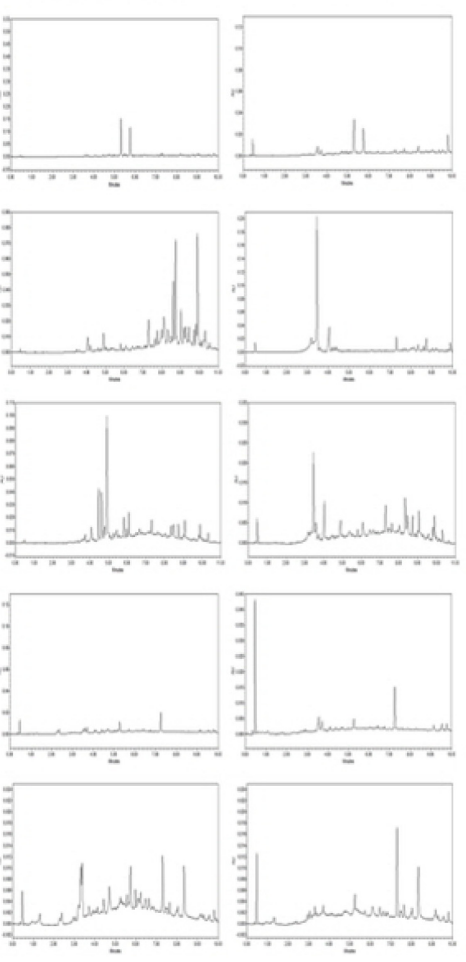

\section{Statistical analysis}

All experiments were performed in triplicate, and data were expressed as mean \pm SD values. Statistical significance was determined

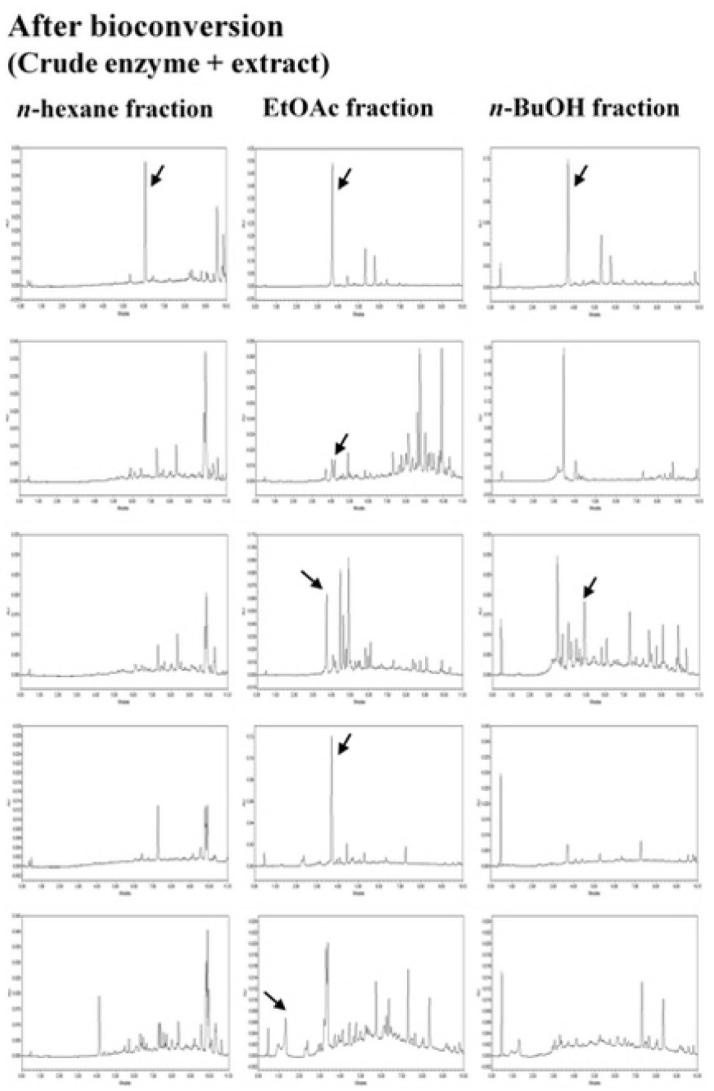

Fig. 1 Comparison of UPLC chromatograms of each fraction before and after bioconversion by A.kawachii treatment. Arrows represent new peaks. (A) Mori Folium, (B) Mori Cortex, (C) Mori Ramulus, (D) Mori Fructus, (E) Loranthi Ramulus

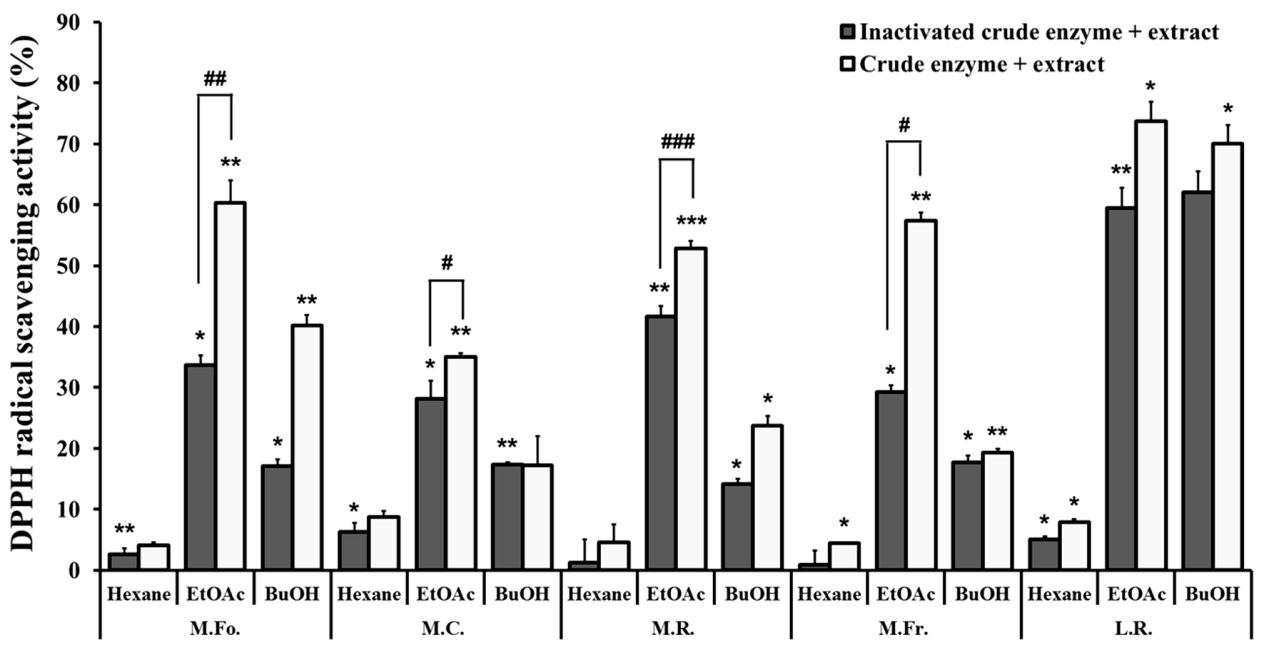

Fig. 2 DPPH radical scavenging activity of each fraction at $100 \mathrm{ppm}$. Bioconversion significantly enhanced DPPH radical-scavenging activity of each fraction, especially the EtOAc soluble fraction. M.Fo.; Mori Folium, M.C.; Mori Cortex, M.R.; Mori Ramulus, M.Fr.; Mori Fructus, L.R.; Loranthi Ramulus. Values represents mean $\pm \mathrm{SD}$ of relative OD obtained from three independent experiments. ${ }^{*} p<0.05,{ }^{* *} p<0.01$ and ${ }^{* * *} p<0.001$ when compared with the control. ${ }^{\#} p<0.05,{ }^{\#} p<0.01$ and ${ }^{\# \#} p<0.001$ when compared with bioconversion of the EtOAc soluble fraction 

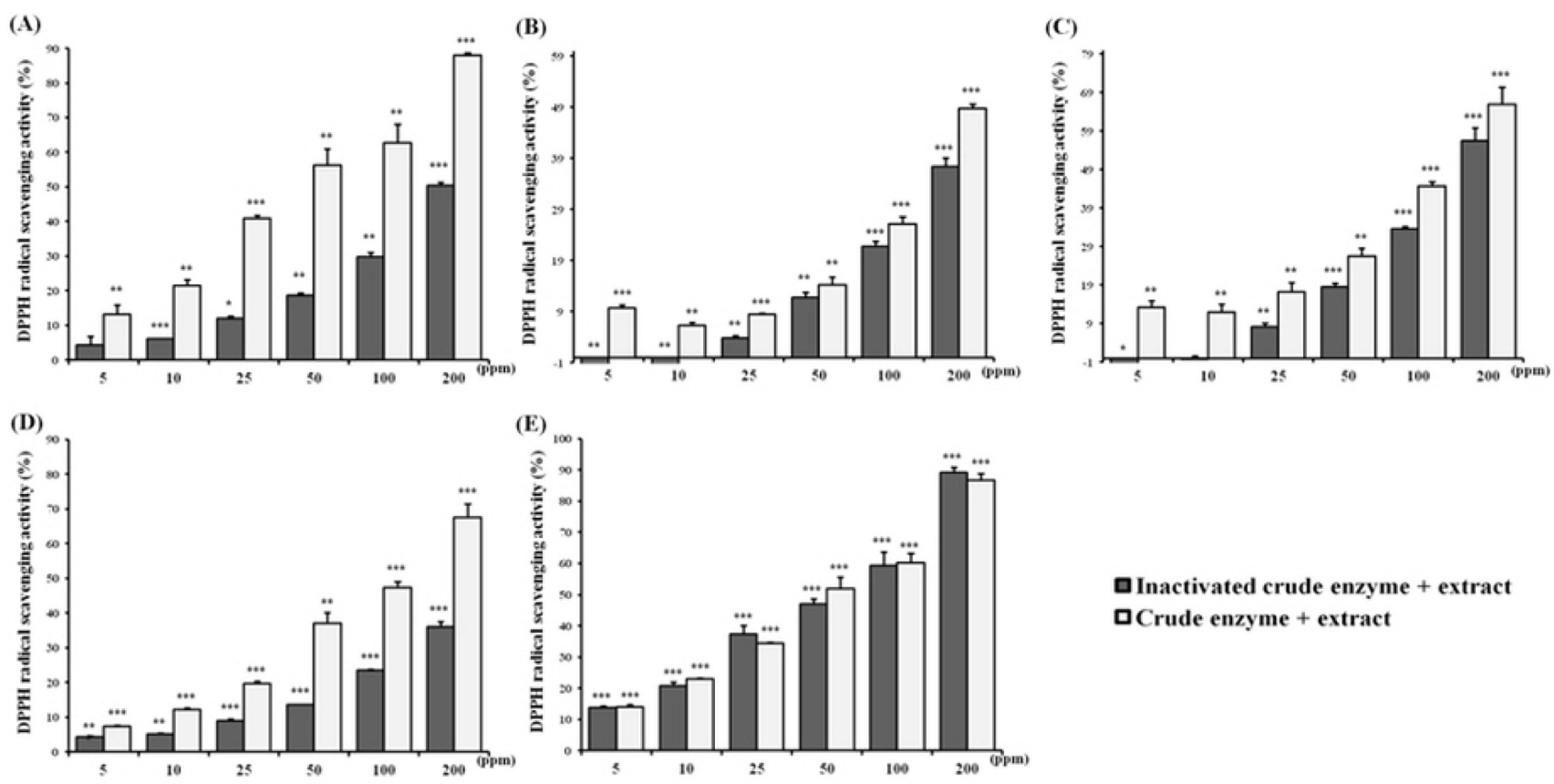

Inactivated crude enzyme + extract 口Crude enzyme + extract

Fig. 3 DPPH radical scavenging activity of EtOAc fractions. Bioconversion enhanced DPPH radical scavenging activity in a dose-dependent manner in EtOAc fractions. Mori Folium was increased to the greatest extent to $37.55 \pm 1.67 \%$ than before bioconversion at 200 ppm. (A) Mori Folium, (B) Mori Cortex, (C) Mori Ramulus, (D) Mori Fructus, (E) Loranthi Ramulus. Values represents mean \pm SD of relative OD obtained from three independent experiments performed. ${ }^{*} p<0.05,{ }^{* *} p<0.01$ and ${ }^{* * *} p<0.001$ when compared with the control
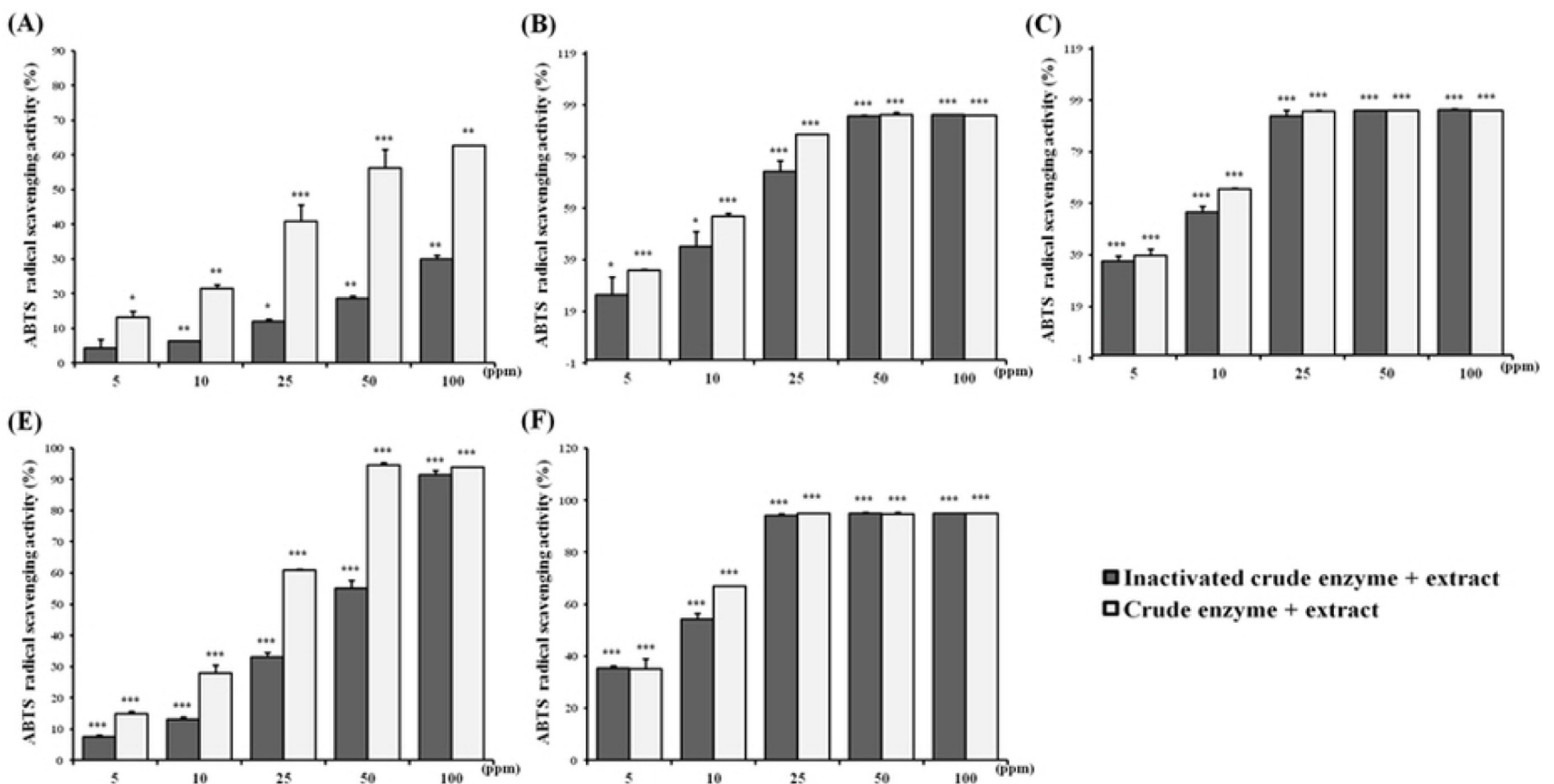
口Inactivated crude enzyme + extract
QCrude enzyme + extract

Fig. 4 Bioconversion enhanced ABTS radical scavenging activity in a dose-dependent manner in EtOAc fractions. Mori Folium and Mori Fructus were increased to $37.60 \pm 1.87 \%$ and $39.50 \pm 0.65 \%$ than before bioconversion at $50 \mathrm{ppm}$. (A) Mori Folium, (B) Mori Cortex, (C) Mori Ramulus, (D) Mori Fructus, (E) Loranthi Ramulus. Values represents mean \pm SD of relative OD obtained from three independent experiments. ${ }^{*} p<0.05,{ }^{* *} p<0.01$ and ${ }^{* * *} p<0.001$ when compared with the control 
(A)

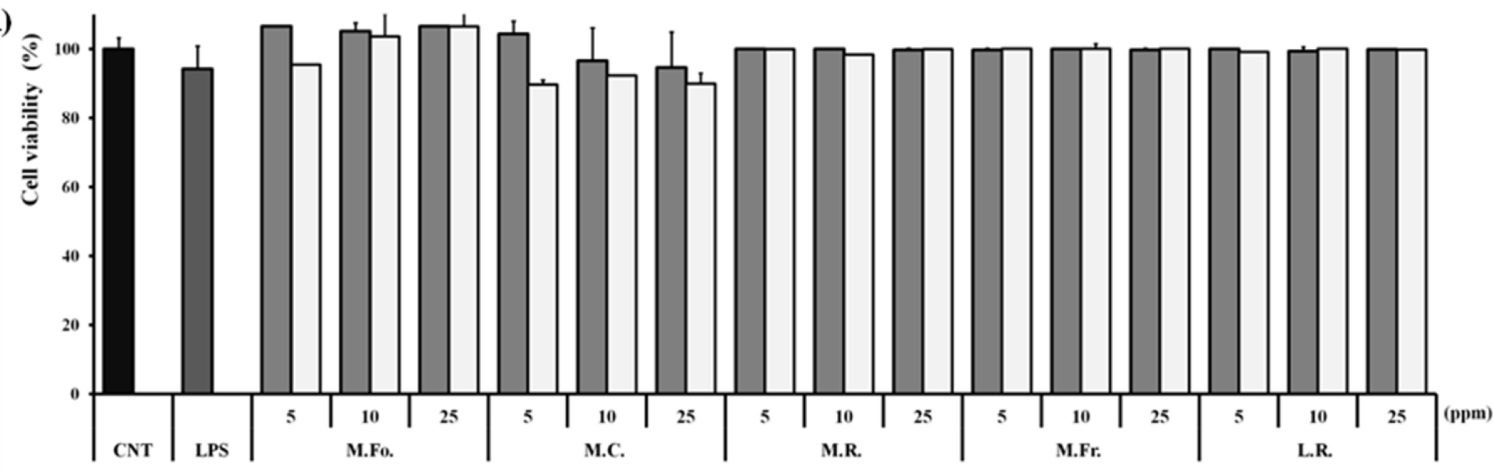

a Inactivated crude enzyme + extract 口Crude enzyme + extract

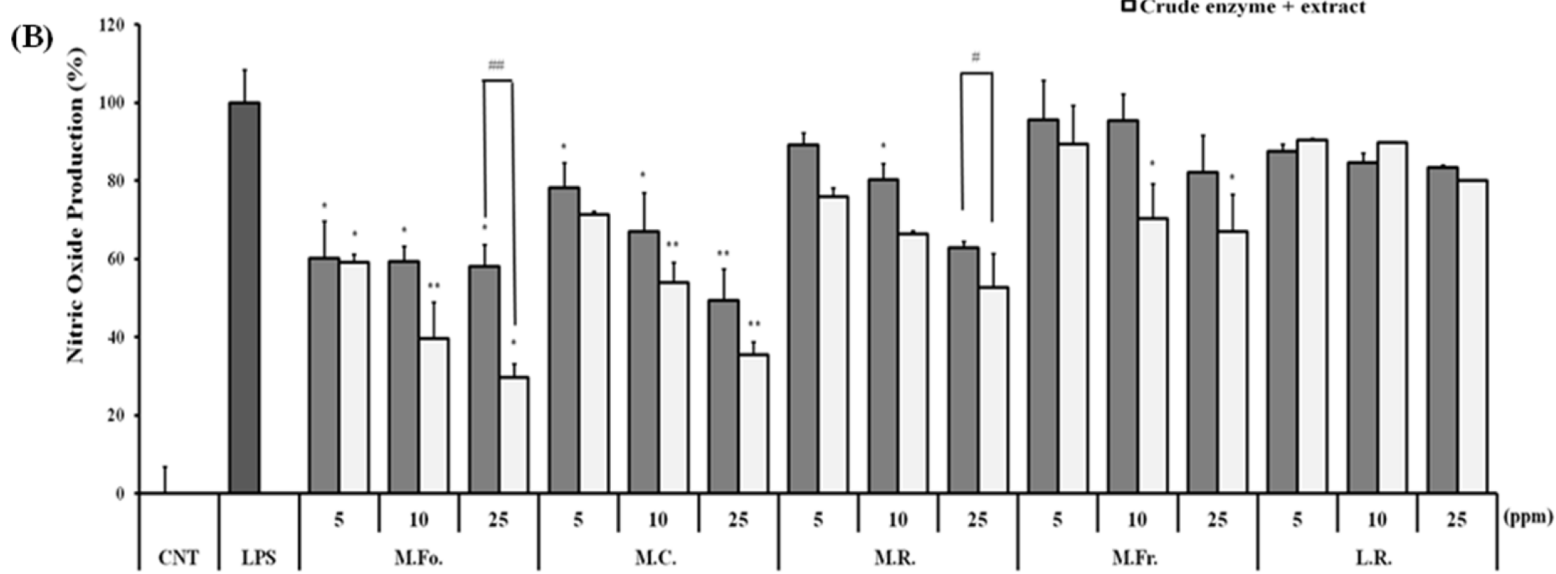

Fig. 5 Inhibitory effect of EtOAc-fractions on nitric oxide production in RAW 264.7 cells. RAW 264.7 cells were treated with EtOAc-soluble fractions $(5,10$ and $25 \mathrm{ppm})$ for $24 \mathrm{~h}$, and cell viability was determined using the MTT assay. RAW 264.7cells were pretreated with EtOAc-soluble fractions (5, 10 and $25 \mathrm{ppm})$ for $1 \mathrm{~h}$, followed by stimulation with LPS $(1 \mu \mathrm{g} / \mathrm{mL})$. After $24 \mathrm{~h}$ of incubation, NO levels in the culture supernatants were determined. Mori Folium showed remarkable inhibition of NO production in LPS-stimulated RAW 264.7 cells at 25 ppm without cytotoxicity. M.Fo.; Mori Folium, M.C.; Mori Cortex, M.R.; Mori Ramulus, M.Fr.; Mori Fructus, L.R.; Loranthi Ramulus. (A) Cell viability of RAW 264.7 cells. (B) Nitric oxide production (\%). Values represent mean $\pm \mathrm{SD}$ of relative OD obtained from three independent experiments performed. ${ }^{*} p<0.05$ and ${ }^{* *} p<0.01$ when compared with LPS-treated cells. ${ }^{\#} p<0.05$ and ${ }^{\#} p<0.01$ when compared with bioconversion of the EtOAc-soluble fraction

using one-way analysis of variance (ANOVA), followed by Tukey's tests. $\mathrm{P}$ values $<0.05$ were considered to be significant.

\section{Results}

\section{Effects of bioconversion on changes UPLC patterns}

To compare the UPLC patterns of the activated enzyme-treated group and inactivated enzyme-treated group (control group), we performed UPLC analysis. Each fraction showed modifications in the composition of compounds due to bioconversion. EtOAc soluble fractions of Mori Folium were significantly changed, and showed a new peak ( $t_{\mathrm{R}}, 3.7 \mathrm{~min}$., Fig. 1$)$.

\section{Fractions exhibit free radical-scavenging activity}

To investigate the effects of antioxidants by free-radical scavenging, we used DPPH and ABTS assays. Effect of each fraction of the activated enzyme-treated group and inactivated enzyme-treated group (control group) on DPPH radical scavenging activity was evaluated at $100 \mu \mathrm{g} / \mathrm{mL}$, and the EtOAc soluble fractions were found to be most effective after bioconversion (Fig. 2). Mori Folium was significantly increased activity in a dose-dependent manner, and about 2-3 fold increase in activity was observed by bioconversion at 50, 100, and 200 ppm (Fig. 3).

The other evaluation by ABTS assay also showed that Mori Folium had significantly increased activity in a dose-dependent manner, and about 2-3 fold increase in activity was observed by bioconversion (Fig. 4). These results suggest that bioconversion enhanced the DPPH and ABTS radical scavenging effects of mulberry trees, especially Mori Folium.

Effects of EtOAc-soluble fractions of mulberry trees that underwent bioconversion, on LPS-induced NO production, and expression of iNOS and COX-2 in RAW 264.7 cells

We first examined the effects of bioconverted EtOAc-soluble fractions of mulberry trees, on the LPS-induced NO production 
(A)

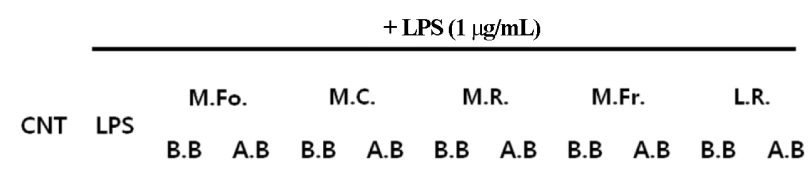

iNOS

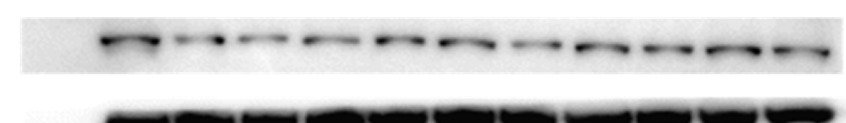

cox-2

$\beta$-actin
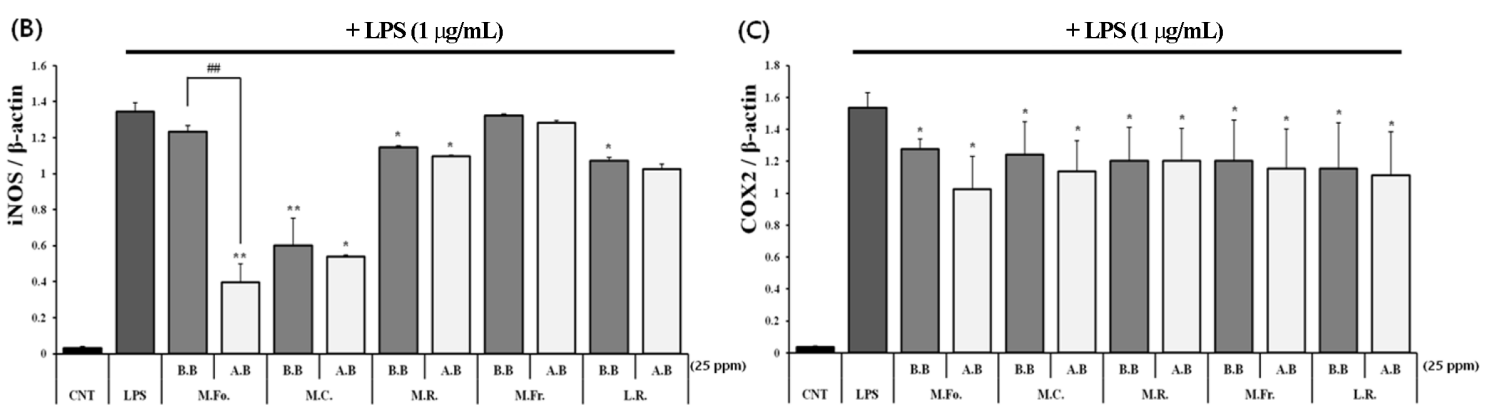

Fig. 6 Effect of EtOAc soluble fractions on iNOS and COX-2 protein expression levels in LPS-stimulated RAW 264.7 cells. RAW 264.7 cells were pretreated with the indicated concentrations of EtOAc soluble fractions at $25 \mathrm{ppm}$ for $1 \mathrm{~h}$ and then stimulated with LPS $(1 \mu \mathrm{g} / \mathrm{mL})$ for $24 \mathrm{~h}$. Cellular proteins were used for the detection of iNOS and COX-2 by western blotting. $\beta$-actin was used as the loading control. M.Fo.; Mori Folium, M.C.; Mori Cortex, M.R.; Mori Ramulus, M.Fr.; Mori Fructus, L.R.; Loranthi Ramulus. B.B; before bioconversion (Inactivated crude enzyme + extract), A.B; after bioconversion (Crude enzyme + extract). ${ }^{*} p<0.05$ and ${ }^{* *} p<0.01$ when compared with treatment with LPS only. ${ }^{*} p<0.01$ when compared with bioconversion of the EtOAc-soluble fraction

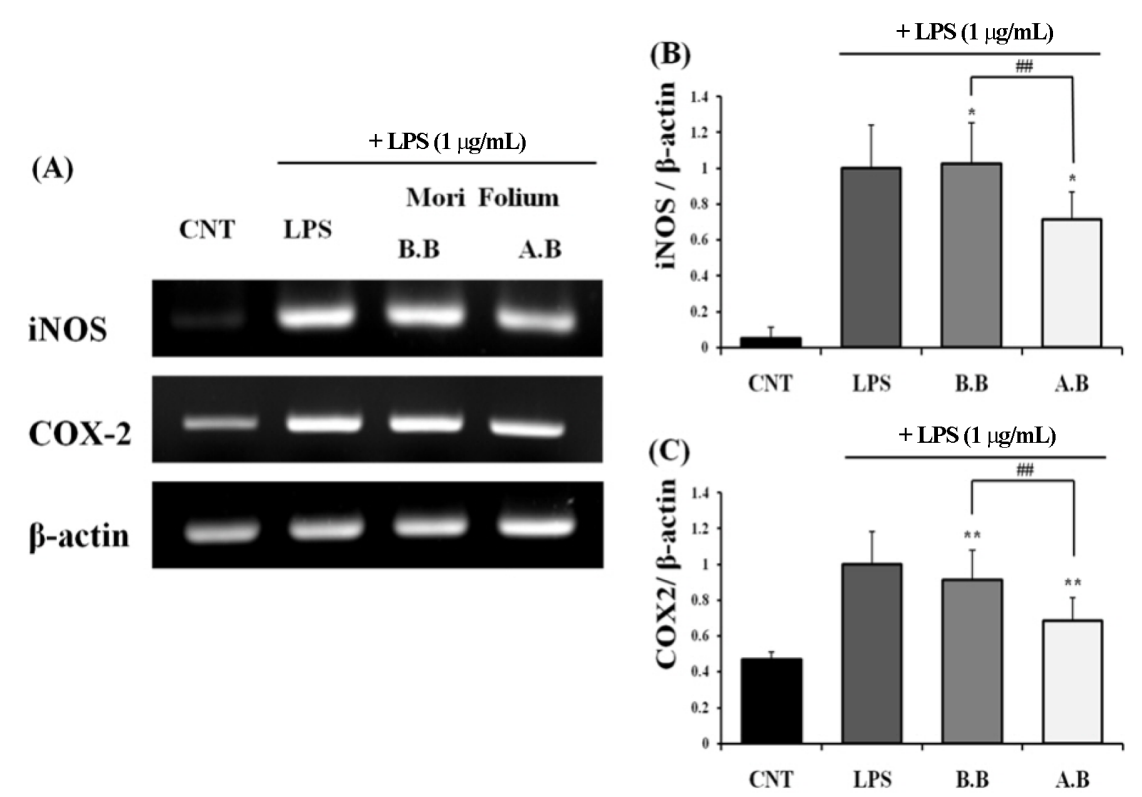

Fig. 7 Effect of EtOAc fractions of Mori Folium that underwent bioconversion (EMB) on LPS-induced mRNA expression levels of iNOS and COX-2 in RAW 264.7 cells. For mRNA expression, RAW 264.7 cells were pretreated with EMB at $25 \mathrm{ppm}$ for $1 \mathrm{~h}$ and then stimulated with LPS (1 $\mu \mathrm{g} / \mathrm{mL})$ for $24 \mathrm{~h}$. Total RNA was isolated, and mRNA levels of iNOS and COX-2 were then measured using RT-PCR. $\beta$-actin was used as the internal control. Quantification of relative band intensities from three independent experiments was performed. B.B; before bioconversion (Inactivated crude enzyme + extract), A.B; after bioconversion (Crude enzyme + extract). ${ }^{*} p<0.05$ and ${ }^{* *} p<0.01$ when compared with treatment with LPS only. ${ }^{\#} p<0.01$ when compared with before bioconversion 

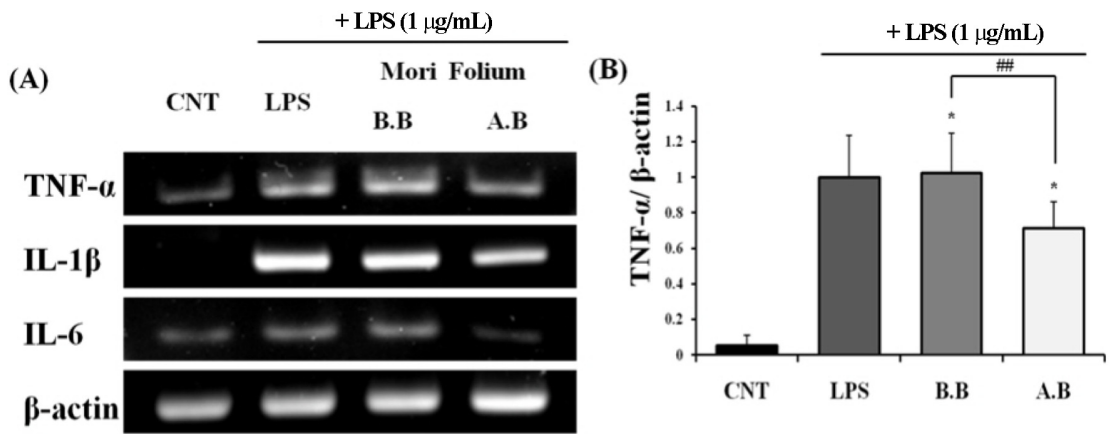

(C)
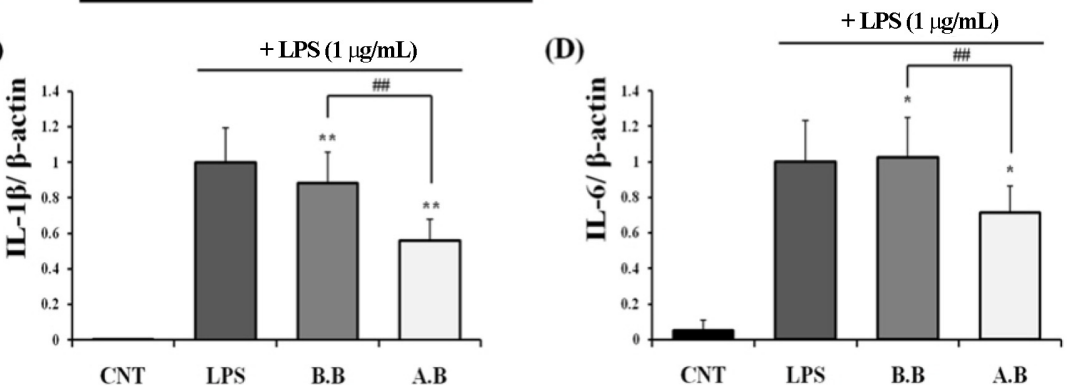

Fig. 8 Effect of EMB on LPS-induced TNF- $\alpha$, IL-1 $\beta$, and IL-6 release. RAW 264.7 cells were pretreated with EMB at 25 ppm for $1 \mathrm{~h}$ and then stimulated with LPS $(1 \mu \mathrm{g} / \mathrm{mL})$ for $24 \mathrm{~h}$. Total RNA was isolated, and mRNA levels of TNF- $\alpha$, IL-1 $\beta$, and IL-6 were then measured using RT-PCR. $\beta$ actin expression was used as the internal control. Quantification of relative band intensities from three independent experiments was performed. B.B; before bioconversion (Inactivated crude enzyme + extract), A.B; after bioconversion (Crude enzyme + extract). $* p<0.05$ and $* * p<0.01$ when compared with treatment with LPS only. ${ }^{\#} p<0.01$ when compared with before bioconversion
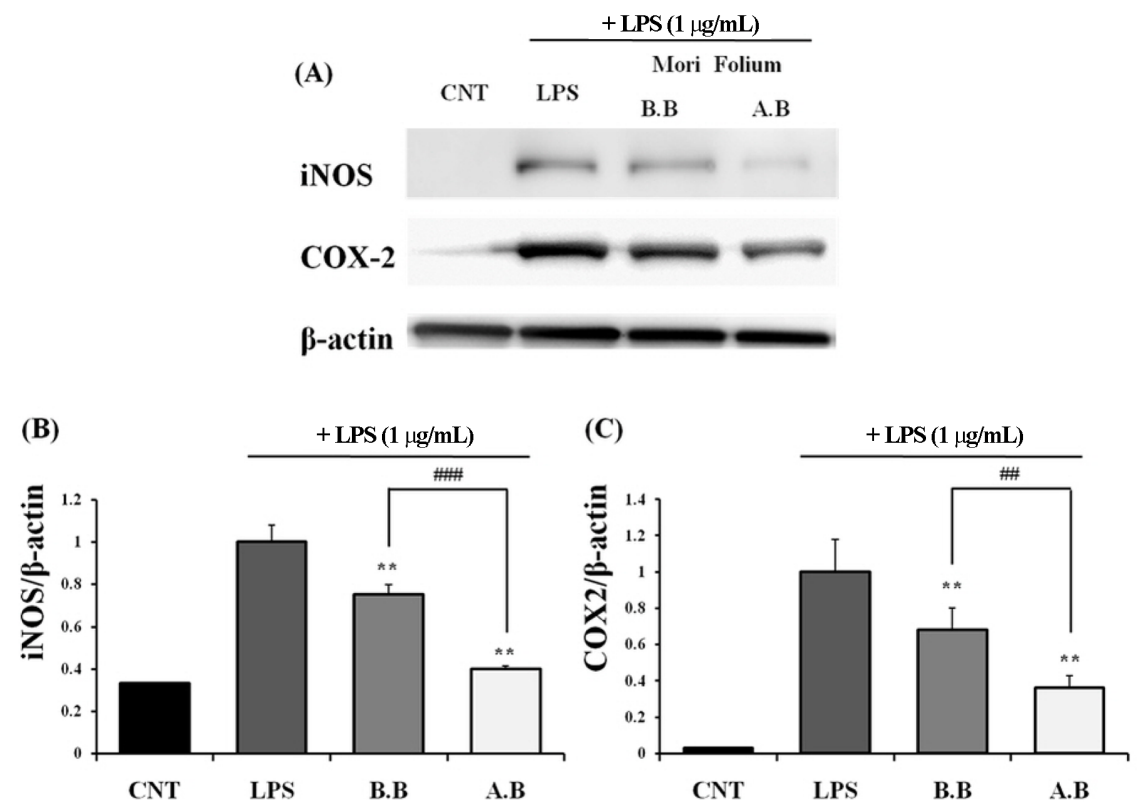

Fig. 9 Effect of EMB on iNOS and COX-2 protein expression levels in LPS-stimulated RAW 264.7 cells. RAW 264.7 cells were pretreated with EMB at $25 \mathrm{ppm}$ for $1 \mathrm{~h}$ and then stimulated with LPS $(1 \mu \mathrm{g} / \mathrm{mL})$ for $24 \mathrm{~h}$. Cellular proteins were used for the detection of iNOS and COX-2 by western blotting. $\beta$-actin was used as the loading control. B.B; before bioconversion (Inactivated crude enzyme + extract), A.B; after bioconversion (Crude enzyme + extract). ${ }^{* *} p<0.01$ when compared with treatment with LPS only. ${ }^{\#} p<0.01$ and ${ }^{\# \#} p<0.001$ when compared with before bioconversion

and potential cytotoxicity in RAW 264.7 cells. LPS stimulation greatly increased the NO production, but pretreatment of EtOAcsoluble fractions at $5-25 \mu \mathrm{g} / \mathrm{mL}$ significantly inhibited LPS- induced NO production (Fig. 5). Especially, at $25 \mu \mathrm{g} / \mathrm{mL}$, EtOAc soluble fractions of Mori Folium that underwent bioconversion, inhibited the NO production by about $28.11 \pm 0.29 \%$. 
(A)

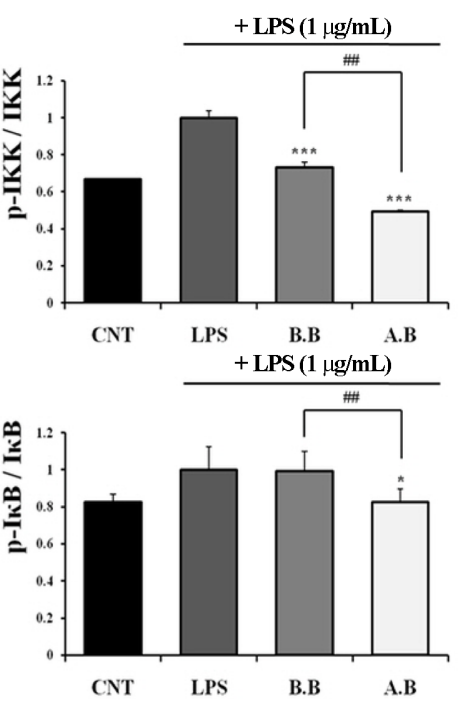

(B)

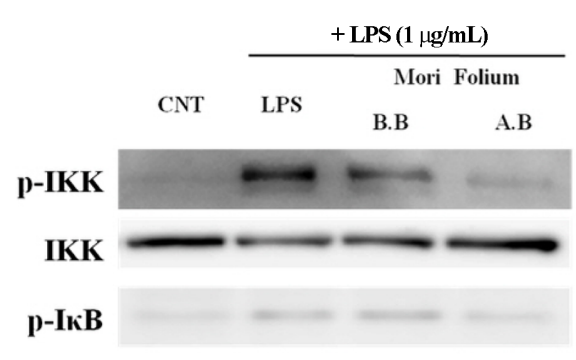

IкB
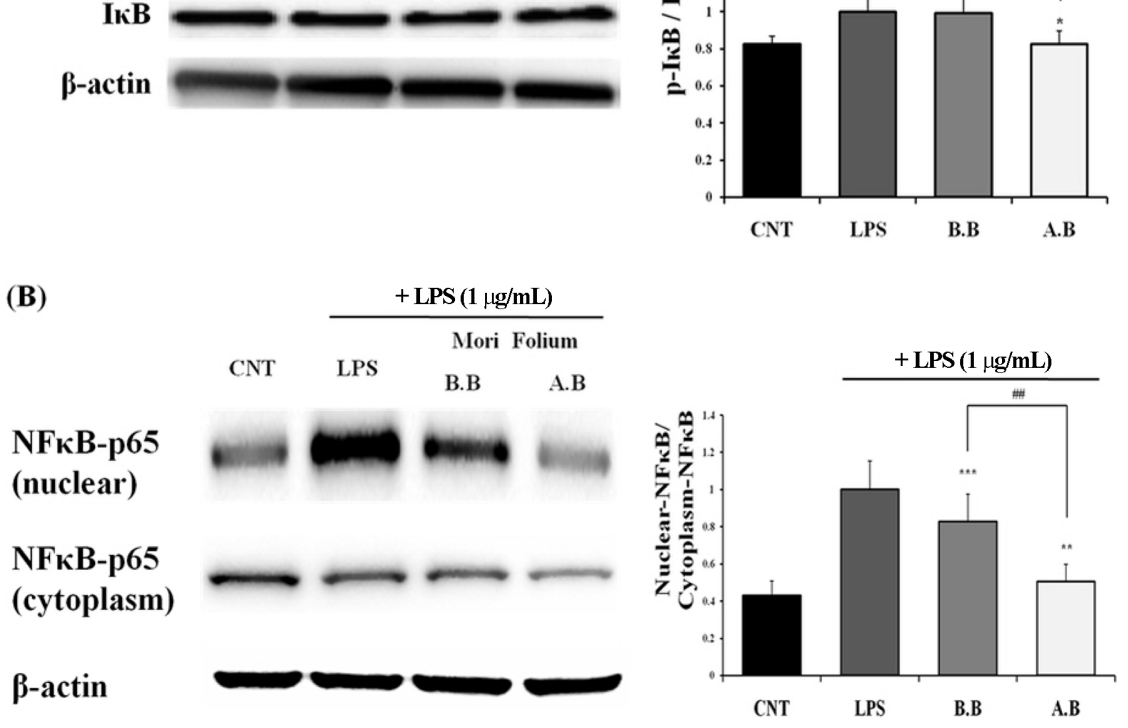

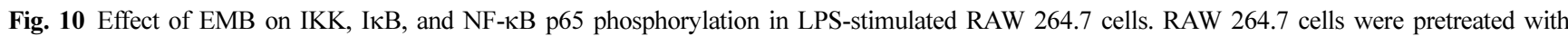
EMB at $25 \mathrm{ppm}$ for $1 \mathrm{~h}$ and then stimulated with LPS $(1 \mu \mathrm{g} / \mathrm{mL})$ for $24 \mathrm{~h}$. Cellular proteins were used for the detection of phosphorylated forms of

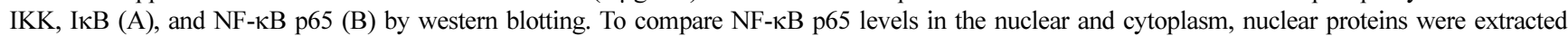
using the Nuclear Protein Extraction Kit. $\beta$-actin was used as the loading control. B.B; before bioconversion (Inactivated crude enzyme + extract), A.B; after bioconversion (Crude enzyme + extract). ${ }^{*} p<0.05,{ }^{* *} p<0.01$ and ${ }^{* * *} p<0.001$ when compared with treatment with LPS only. ${ }^{*} p<0.01$ when compared with before bioconversion

We further determined the expression of iNOS and COX-2 to understand their anti-inflammatory mechanism. Western blot analysis showed that iNOS and COX-2 protein concentrations were elevated by LPS stimulation. However, treatment of EtOAc soluble fractions that underwent bioconversion, attenuated the iNOS and COX-2 protein levels at $25 \mu \mathrm{g} / \mathrm{mL}$ (Fig. 6). Of these, Mori Folium significantly inhibited the expression of iNOS protein level. Accordingly, these data suggest that EtOAc-soluble fractions of Mori Folium that underwent bioconversion have higher inhibitory activities at $25 \mu \mathrm{g} / \mathrm{mL}$, against LPS-induced $\mathrm{NO}$ production, and iNOS and COX-2 protein expression, than other segments of the mulberry tree.

Effects of EtOAc soluble fraction of Mori Folium that underwent bioconversion (EMB) on LPS-induced mRNA expression levels of iNOS, COX-2, TNF- $\alpha$, IL-1 $\beta$ and IL-6 in RAW 264.7 cells

Immoderate inflammatory cytokines, such as TNF- $\alpha$, IL-1 $\beta$, and
IL-6 are important mediators that regulate responses to the inflammatory molecular mechanism. Therefore, we investigated whether EMB can inhibit the production of LPS-induced proinflammatory cytokines. To confirm the expression of inflammatory cytokines by treating EMB in RAW 264.7 cells with LPS, total cellular mRNA was extracted to perform the RT-PCR assay. Results indicate that the LPS-stimulated RAW 264.7 cells show an increase in the iNOS, COX-2, TNF- $\alpha$, IL-1 $\beta$ and IL- 6 mRNA levels. However, treatment of EMB significantly decreased the mRNA expressions of inflammatory cytokines, when compared with the control group of Mori Folium (Figs. 7 and 8). These results show that EMB can mediate the inhibition of these inflammatory cytokines by probably regulating the protein levels.

\section{Effects of EMB on iNOS and COX-2 protein expressions in} LPS-induced RAW 264.7 cells

Although we had already determined that treatment of EMB decreased expressions of iNOS and COX-2 mRNA revel, we 


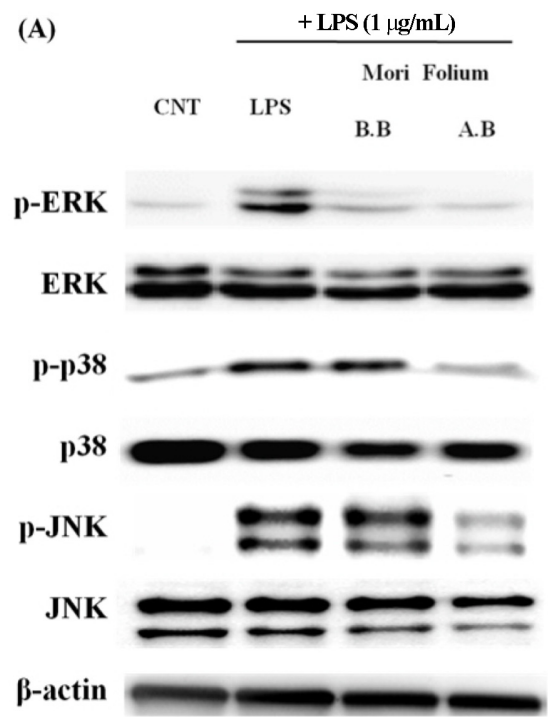

(B)

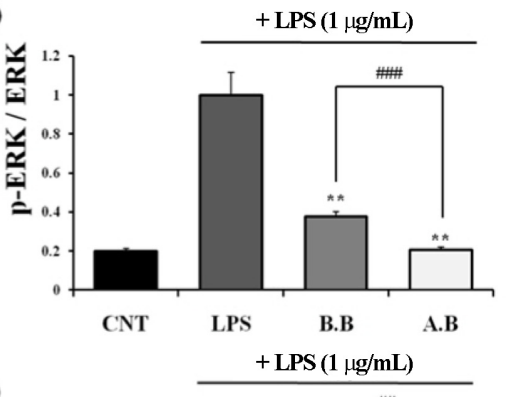

(C)

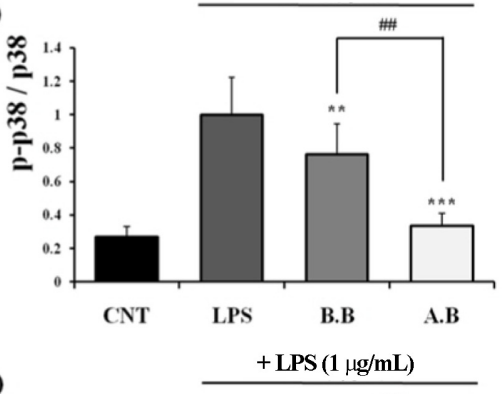

(D)

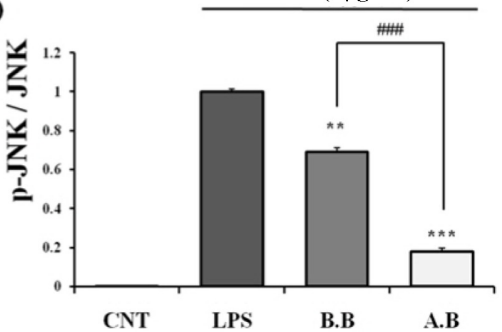

Fig. 11 Effect of EMB on MAPK phosphorylation in LPS-stimulated RAW 264.7 cells. RAW 264.7 cells were pretreated with EMB at 25 ppm for $1 \mathrm{~h}$ and then stimulated with LPS $(1 \mu \mathrm{g} / \mathrm{mL})$ for $24 \mathrm{~h}$. Cellular proteins were used for the detection of phosphorylated or total forms of ERK1/2 (B), p38 (C) and JNK (D) by western blotting. B.B; before bioconversion (Inactivated crude enzyme + extract), A.B; after bioconversion (Crude enzyme + extract). ${ }^{* *} p<0.01$ and $* * * p<0.001$ when compared with treatment with LPS only. ${ }^{\#} p<0.01$ and ${ }^{\# \# \#} p<0.001$ when compared with before bioconversion

further evaluated these signals at the protein level by using western blot to confirm their anti-inflammatory signaling. As shown in Fig. 9, iNOS and COX-2 protein expressions were increased up to $1.00 \pm 0.08$-fold by LPS, while those treated by EMB was significantly reduced to $0.40 \pm 0.01$-fold and $0.36 \pm 0.07$-fold, respectively. These results therefore show that EMB was highly effective in reducing the iNOS and COX-2 protein levels.

Effects of EMB on LPS-induced NF- $\kappa B$ nuclear translocation, and IKK and IKB phosphorylation in RAW 264.7 cells

NF- $\kappa \mathrm{B}$ is an important factor in the inflammatory response in RAW 264.7 cells. Hyperphosphorylation of IKK and IKB, and subsequent phosphorylation, are steps in NF- $\kappa B$ activation. When $\mathrm{NF}-\kappa \mathrm{B}$ is activated, it induces p 65 nuclear localization and expression of several inflammatory cytokine genes. Therefore, we evaluated whether inhibition of the inflammatory effects by EMB is mediated via the NF- $\kappa$ B pathway. IKK, I $\kappa$ B and NF- $\kappa$ B proteins were evaluated using the western blot assay. The results indicated that EMB treatment significantly inhibited the phosphorylation of IKK

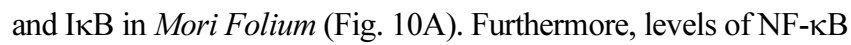

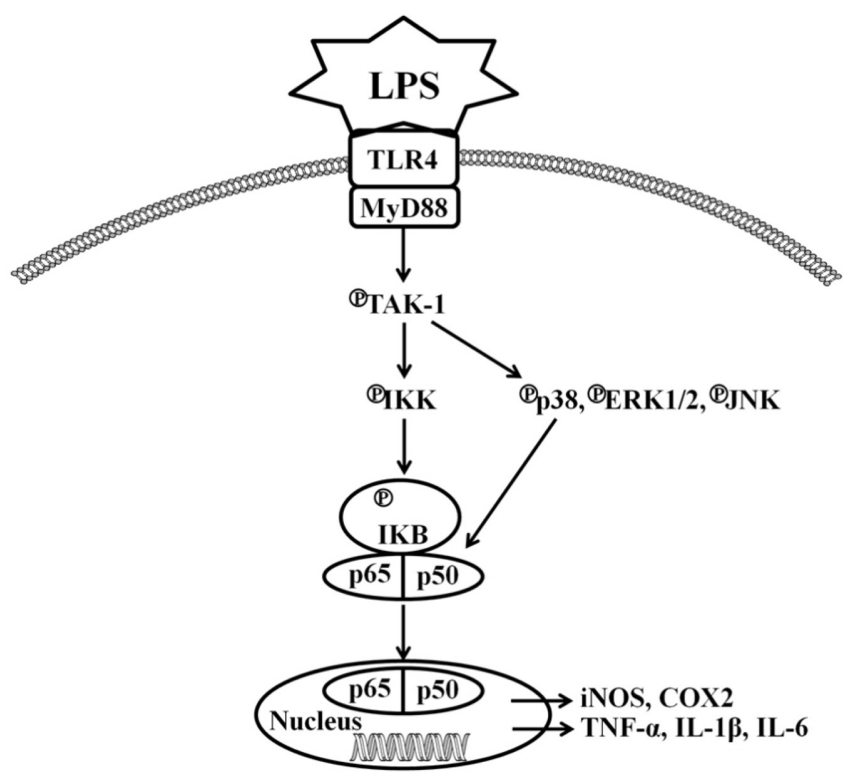

Fig. 12 Mechanism of inflammation in LPS-stimulated RAW 264.7 cells [30] 
p65 in the nucleus were remarkably increased by exposure to LPS alone, but EMB reduced the LPS-mediated nuclear translocation of NF-kB p65 in Mori Folium (Fig. 10B).

These results implied that EMB might block LPS-stimulated $\mathrm{NF}-\kappa \mathrm{B}$ activation by regulating the IKK and I $\mathrm{B}$ phosphorylation.

\section{Effects of EMB on LPS-induced MAPK phosphorylation in RAW 264.7 cells}

Several stimuli that activate NF- $\kappa$ B also activate MAPKs, which induce the expression of other proinflammatory genes. Three major subfamilies of MAPKs have been defined, hence we confirmed whether the MAPK pathways are included in the inhibitory effects of EMB on the release of proinflammatory mediators, by examining the phosphorylation of ERK1/2, p38, and JNK. However, co-treatment with EMB significantly blocked phosphorylation in Mori Folium. These results suggest that the MAPK signaling pathway, which plays critical roles in inflammation, is inhibited by bioconversion.

\section{Discussion}

The mulberry tree is known to have anti-cancer, anti-obesity, antioxidant, as well as anti-inflammatory activities [25]. However, bioconversion of the mulberry tree with the crude enzyme extract of $A$. kawachii has not yet been reported. Furthermore, effects of different parts of the mulberry tree (Morus alba L.) that underwent bioconversion are unknown.

In this study, we demonstrated that bioconversion enhanced the anti-oxidant and anti-inflammatory effects of five different parts of the mulberry tree (Morus alba L.), and the most effective part was the mulberry leaf (Mori Folium).

We first evaluated the changes in the chemical composition after bioconversion, using UPLC analysis. We observed that EtOAc-soluble fractions of the five different segments of the mulberry tree that underwent bioconversion, displayed new peaks when compared with the inactivated enzyme treated group. We expected that bioconversion with $A$. kawachii crude enzyme would change the anti-oxidant activity, since the crude enzyme extract prepared from A. kawachii contains beta-glucosidase [1]. Several studies suggest that beta-glucosidase enhances the antioxidant effects by hydrolyzing $\beta$-glucosidic bonds of the conjugated form to sugar residues linked to hydroxyl groups [26]. We determined the antioxidant activity using two different tests, namely DPPH and ABTS assays. The DPPH assay is a convenient method for measuring antioxidant capacity by scavenging of free radicals. The ABTS assay is used to evaluate the hydrophilic and lipophilic antioxidant capacity by scavenging cation radicals, because of its solubility in aqueous and organic solvents [23]. The results reveal that the DPPH radical-scavenging effects of each fraction of the five different parts of the mulberry tree were increased by bioconversion, especially the EtOAc-soluble fraction at $100 \mu \mathrm{g} / \mathrm{mL}$. Therefore, we evaluated the DPPH radical-scavenging effects of EtOAc-soluble fractions at various concentrations, and determined the ABTS radical-scavenging activity in a similar manner. Bioconversion enhanced the DPPH and ABTS radicalscavenging activities in a dose-dependent manner: leaf $>$ fruit $>$ root $>$ twig $>$ mistletoe of the mulberry tree. We expected these samples have anti-inflammatory effects because antioxidants inhibit the ROS generation by activating pro-inflammatory cytokines [6]. ROS especially stimulates NO [27]. Thus, we determined the antiinflammatory effects of five different parts of the mulberry tree in LPS-stimulated RAW 264.7 cells by evaluating the NO production, and expression of inflammatory proteins such as iNOS and COX2. The results show that bioconversion enhanced the inhibition of NO production in Mori Folium at a concentration of $25 \mu \mathrm{g} / \mathrm{mL}$. Furthermore, Mori Folium that underwent bioconversion, attenuated the iNOS and COX-2 protein levels, which are important enzymes mediating the inflammatory processes. Overall, bioconversion enhanced the radical-scavenging effects and anti-inflammatory properties of Mori Folium, thus confirming the anti-inflammatory mechanism of Mori Folium that had undergone bioconversion. As shown in Fig. 12, the inflammation mechanism in RAW 264.7 cells is initiated with LPS-stimulation. LPS activates the proinflammatory cytokines such as TNF- $\alpha$, IL- $1 \beta$, and IL-6, which induce the expression of iNOS and COX-2 through the activation of NF- $\kappa \mathrm{B}$ and MAPK pathway, and thereby increase NO production $[28,29]$. In this study, we found that bioconversion significantly enhanced the effect of Mori Folium by inhibiting the production of TNF- $\alpha$, IL-1 $\beta$, IL-6, iNOS, and COX-2. Furthermore, it inhibited the phosphorylation of IKK and IאB, and blocked the $\mathrm{NF}-\mathrm{\kappa B}$ p65 translocation into the nucleus. MAPK signaling proteins, such as ERK1/2, p38, and JNK, were also markedly inhibited by bioconversion. Taken together, our results demonstrate that bioconversion enhanced the anti-oxidant and anti-inflammatory effects of Mori Folium. Therefore, it may be useful as a potential anti-oxidant and anti-inflammatory agent.

In summary, bioconversion enhanced the anti-oxidant effects of Mori Folium by improving the DPPH and ABTS radical scavenging and anti-inflammatory signaling, such as decreased NO production. Moreover, Mori Folium that underwent bioconversion inhibited the production of pro-inflammatory cytokines (TNF- $\alpha$, IL- $1 \beta$ and IL-6), iNOS and COX-2, by regulating the phosphorylation of IKK and IкB. Thus, Mori Folium that underwent bioconversion may have preventive and therapeutic functions against various diseases related to oxidative stress and inflammation. Further in vivo studies are required to identify the mechanism in the target organs.

\section{References}

1. Kim SI, Kim JE, So JH, Rhee IK, Chung SK, Lee KB, Yoo YC (2004) Changes in chemical composition and biological activities Oriental crude drugs by food processing techniques (I)-Changes in liquiritigenin contents 
in licorice extract treated by the crude enzyme extract from Aspergillus kawachii. Kor J Pharmacogn 35: 309-314

2. Yang EJ, Kim SI, Park SY, Bang HY, Jeong JH, So JH, Rhee IK, Song KS (2012) Fermentation enhances the in vitro antioxidative effect of onion (Allium cepa) via an increase in quercetin content. Food Chem Toxico 50: 2042-2048

3. Jeon KS, Hwang IK, Ji GE (2002) Assay of b-glucosidase activity of Bifidobacteria and the hydrolysis of isoflavone glucosides by Bifidobacterium sp. Int-57 insoymilk fermentation. J Microbiol Biotechnol 12: 8-13

4. Balsano C, Alisi A (2009) Antioxidant Effects of Natural Bioactive Compounds. Current Pharmaceutical Design 11: 3063-3073

5. Huang D, Ou B, Prior RL (2005) The chemistry behind antioxidant capacity assays. J Agri Food Chem 53: 1841-1856

6. Naik E, Dixit VM (2011) Mitochondrial reactive oxygen species drive proinflammatory cytokine production. J Exp Med 208: 417-420

7. Conese M, Assael BM (2001) Bacterial infections and inammation in the lungs of cystic brosis patients. Pediatric Infectious Disease Journal 20: 207-213

8. Atabai K, Matthay MA (2002) The pulmonary physician in critical care. 5: Acute lung injury and the acute respiratory distress syndrome: Denitions and epidemiology. Thorax 57: 452-458

9. Rubenfeld GD, Caldwell E, Peabody E, Weaver J, Martin DP, Neff M, Stern EJ, Hudson LD (2005) Incidence and outcomes of acute lung injury. New Eng J Med 353: 1685-1693

10. Ulevitch RJ, Tobias PS (1999) Recognition of Gram-negative bacteria and endotoxin by the innate immune system. Curr Opin Immunol 11: $19-22$

11. Boje KM (2004) Nitric oxide neurotoxicity in neurodegenerative diseases. Frontiers in Bioscience 9: 763-776

12. Hartlage-Rubsamen M, Lemke R, Schliebs R (1999) Interleukin-1beta, inducible nitric oxide synthase, and nuclear factor-kappaB are induced in morphologically distinct microglia after rat hippocampal lipopolysaccharide/ interferon-gamma injection. J Neuroscience Research 57: 388-398

13. Takeuchi H, Jin S, Wang J, Zhang G, Kawanokuchi J, Kuno R, Sonobe Y, Mizuno T, Suzumura A (2006) Tumor necrosis factor-alpha induces neurotoxicity via glutamate release from hemichannels of activated microglia in an autocrine manner. J Biol Chem 281: 21362-21368

14. Katsube T, Imawaka N, Kawano Y, Yamazaki Y, Shiwaku K, Yamane Y (2006) Antioxidant avonol glycosides in mulberry (Morus alba L.) leaves isolated based on LDL antioxidant activity. Food Chem 97: 25-31

15. Zhang W, Han F, He J, Duan C (2008) HPLC-DAD-ESI-MS/MS analysis and antioxidant activities of nonanthocyanin phenolics in mulberry (Morus alba L.). J Food Sci 73: 512-518

16. Huang HP, Shih YW, Chang YC, Hung CN, Wang CJ (2008) Chemoinhibitory effect of mulberry anthocyanins on melanoma metastasis involved in the Ras/PI3K pathway. J Agric Food Chem 56: 9286-9293

17. Chen CC, Liu LK, Hsu JD, Huang HP, Yang MY (2005) Mulberry extract inhibits the development of atherosclerosis in cholesterol-fed rabbits. Food Chem 91: 601-607

18. Liu LK, Chou FP, Chen YC, Chyau CC, Ho HH (2009) Effects of Mulberry (Morus alba L.) Extracts on Lipid Homeostasis in Vitro and in Vivo. J Agric Food Chem 57: 7605-7611

19. Kim SB, Chang BY, Jo YH, Lee SH, Han SB (2013) Macrophage activating activity of pyrrole alkaloids from Morus alba fruits. J Ethnopharmacol 145: 393-396

20. Kang TH, Hur JY, Kim HB, Ryu JH, Kim SY (2006) Neuroprotective effects of the cyanidin-3-O-beta-D-glucopyranoside isolated from mulberry fruit against cerebral ischemia. Neurosci Lett 391: 122-126

21. Nidome T, Takahashi K, Goto Y, Goh S, Tanaka N, Kamei K, Ichida M, Hara S, Akaike A, Kihara T (2007) Mulberry leaf extract prevents amyloid beta-peptide bril formation and neurotoxicity. Neuro report 18 : 813-816

22. Blois MS (1958) Antioxidant determination by the use of a stable free radical. Nature 181: 1199-1200

23. Re R, Pellegrini N, Proteggente A, Pannala A, Yang M, Rice-Evans C (1999) Antioxidant activity applying an improved ABTS radical cation decolorization assay. Free Radic Biol Med 26: 1231-1237

24. Heo SJ, Yoon WJ, Kim KN, Ahn GN, Kang SM, Kang DH, Affan Abu, Oh CH, Jung WK, Jeon YJ (2010) Evaluation of anti-inflammatory effect of fucoxanthin isolated from brown algae in lipopolysaccharidestimulated RAW 264.7 macrophages. Food Chem Toxico 48: 2045-2051

25. Łochyńska M, Oleszak G (2011) Multi-use of the white mulberry (Morus alba L.). Ecological questions 15.1: 91-95

26. Georgetti SR (2009) Enhanced in vitro and in vivo antioxidant activity and mobilization of free phenolic compounds of soybean flour fermented with different [beta]-glucosidase-producing fungi. J Applied Microbiology 106: $1364-5072$

27. Reddy BD, Reddanna P (2009) Chebulagic acid (CA) attenuates LPSinduced inflammation by suppressing NF- $\mathrm{B}$ and MAPK activation in RAW 264.7 macrophages. Biochem Biophys Res Commun 381: 112117

28. Kawai T, Akira S (2006) TLR signaling. Cell Death Differ 13: 816-825

29. Kim KN, Heo SJ, Yoon WJ, Kang SM, Ahn G, Yi TH, Jeon YJ (2010) Fucoxanthin inhibits the inflammatory response by suppressing the activation of NF- $\mathrm{KB}$ and MAPKs in lipopolysaccharide-induced RAW 264.7 macrophages. Eur J Pharmacol 649: 369-375

30. Jung YJ, Jung JI, Cho HJ, Choi MS, Sung MK, Yu R, Kang YH, Park $\mathrm{JH}$ (2014) Berteroin present in cruciferous vegetables exerts potent antiinflammatory properties in murine macrophages and mouse skin. Int $\mathrm{J}$ Mol Sci 15: 20686-20705 